\title{
EFFECT OF OPEN WOUND CARE PROTOCOL ON NURSES' KNOWLEDGE AND PATIENTS WOUND HEALING
}

\section{M.Sc.Manal Tharwat AbouZaid, Dr. Labiba Abd El-Kader Mohamed, Dr.Mossad Mahmud Morshed, Assistant. Dr. Eman Saleh Shahin, Assistant. Dr. Amal Bakr}

\section{Abo-El-Ata}

M.Sc .Medical Surgical Nursing, Faculty of Nursing, Ain Shams University egypt. Professor of Medical-Surgical Nursing, Faculty of Nursing, Caire University, Egypt; Professor of

Surgery, Faculty of Medicine - Mansoura University, Egypt; Assistant Professor of Medical Surgical Nursing,Faculty of Nursing - Port Said University, Egypt assistant Professor Of Medical Surgical Nursing, Faculty Of Nursing -

Port Said Universityegypt

\begin{abstract}
Background:Surgical wounds are of the most devastating injuries. They produce a dramatic change in the patient's life. Nurses are the key persons in directing successful rehabilitation effort to assure patients attain functional capabilities, avoid further disabilities, and prevent complications. Aim:to assess nurses' knowledge regardingopen wound care in the surgical unit, evaluate the effect of a wound care protocol on nurses' knowledge in the surgical unit, and assess patients' wound healing pre- and post-applying wound care protocol in surgical units at Mansoura University and emergency hospitals. Subject and methods: A descriptive exploratory research study were carried out. Study sample:includes two groups first group, consisted of 55nurses from the two hospitals, second group consist 53 adult patients with openwounds, Data collection was accomplished utilizing three tools; Astructured interview for the nurses, wound care observational checklist,Bates-Jensen, Data was collected from both nurses and patients three times; one time before implementing the wound care protocol, and a second time after its implementationthiredthird time after 12 weeks follow up. The result of this study revealed a statistically significant improvement in nurses' knowledge after implementing wound care protocol ( $\mathrm{P}$-value = 0.014 and 0.000 respectively). Additionally, wound degeneration decreased in postprotocol implementation and during follow-up. The wound regeneration significantly improved $(\mathrm{P}$-value $=0.000)$ after implementing the wound care protocol. Conclusion: the study concluded the presence of an improvement in nurses'knowledge after implementing the wound care protocol. Also, the wound healing improved significantly. Recommendations: nurses' knowledge about surgical wound care and infection control in general needs to be updated, through in-service training programs. The hospital should have policies regarding infection control measures, to be reviewed periodically.
\end{abstract}

Keywords: Open Surgical Wounds, Patients, Knowledge, Wound Regeneration, Wound Degeneration, and Assess, Complications, Bates-Jensen, 


\section{INTRODUCTION}

A wound is defined as a break in the continuity of the skin (Schultz et al. 2013). It may arise from an underlying altered physiological state or be primary in origin. As the largest organ in the body, damage to the skin and alteration in its functions can have catastrophic consequence for the individual. Reassuringly, the vast majority of insults to the integrity of the skin heal uneventfully. However, whether it is due to the nature of the injury, or the health of the individual, some wounds have a delayed and protracted course of healing (Falanga 2015).

Wounds can be broadly classified as acute or chronic. Acute wounds usually heal in an ordered, timely fashion, and are typically seen as post-operative wounds, minor lacerations, abrasions, minor burns and scalds and some trauma wounds (McDermottScales et al. 2014). Conversely, chronic wounds do not follow this ordered sequence of events and are characterized by delayed healing, cellular senescence, and recurrent infections. Chronic wounds in particular are common across all health care settings and there is growing evidence that the burden of chronic wounds in Ireland is already high and likely to increase (O’Brien et al. 2016)

Taking care of wounds is a dynamic, complex process and requires specific knowledge of the nursing team, comprising professionals who will develop this care both in prevention and in the specific treatment. One should take into consideration that the wounds are changing rapidly and are resistant to various types of treatment and result of predisposing conditions that prevent normal healing. 2 The practice of care to patients, client's wounds is a specialty within nursing, (Chicano and Drolshagen, 2015). There are multiple variables that affect the wound healing process, such as the condition of wound, patient's age, general health and nutrition, certain drugs, co morbidities, and infections (Lazarus et al., 2016).

Clean surgical wound which is not contaminated or infected will heal by primary intention. Proper wound care involves cleaning the wound, and approximating its edges with suture material, without tension, to make the defect as small as possible. Healing will then proceed over the next few days, and the suture material can usually be removed after 7 to 10 days when the adhesion of the wound is strong enough. The healing process takes much longer, and a wound can only be considered completely healed after 6 to 9 months, when the inflammatory and modulating processes stabilize. 
This process usually leaves a small, neat scar. When a wound is closed with too much tension, it leads to necrosis of the tissue, or if it gets infected, healing becomes delayed, and then the wound heals by secondary intention. The wound in such a case first needs to be cleaned and the infection needs to be controlled before healing can take place. This process takes much longer and usually leaves a large scar when healed (Bonham, 2014).

Postoperative wound infection is a major source of illness and a less frequent cause of death among surgical patients (Nichols, 2014). Postoperative infection is the most common nosocomial infection, and according to the (Center for Disease Control ,2010), reportedthat $67 \%$ of these infections occur at the incision and $33 \%$ occur in an organ or in the space around the surgical site. Surgical wound infection is mostly caused by extrinsic contamination of an intravenous agent (such as Propofol) by the anesthetic personnel who harbored pathogens in lesions on their hands, scalp and in their nares. Lapses in aseptic techniques and reuse of single-use vials for several patients are contributive factors in the occurrence of surgical wound infections (Allen et al., 2013).

\section{Significance of study:}

Prediction through accurate assessment and prevention of wound complications using appropriate measures is one of the most important goals of nursing care. However, for patients who have already developed wound-related complications, timely intervention can reduce morbidity and mortality rates. The concerted effort of nurses, doctors, and other healthcare providers is necessary for optimal outcomes. As a result, a nursing care clinical practice protocol should be developed to assist such individuals in the prevention and treatment of wound complications, which is a challenge in the care of patients.

\section{THE AIM OF STUDY:}

was to evaluate the effect of a wound care protocol on nurses' knowledge,and patients' wound healing in the surgical unit Mansoura university hospital. This aim was achieved through:

- Assess of the nurses' knowledge about wound care

- Design a wound care protocol for nurses 
- Implement the protocol of wound care

- Assess of patients' wound healing, pre- and post-applying the wound care protocol.

\section{Research hypotheses:}

- The level of nurses' knowledge regarding wound care will increase significantly after implementing the wound care protocol.

- The patients' wound healing will be improved after than before implementing the wound care protocol

\section{SUBJECT AND METHODS:}

A quasi-experimental research question designed was used in the current study.

\section{The study sample:}

A convenient sample of two groups; nurses and patients, was used in the current study:

Group 1: Convenient sample of all nursesworking at the general surgical unit who accepted to participate in the study (55 nurses).

Group 2: All patients admitted to the study settings during the time of data collection (6 months) were invited to participate in the study (; 53 with open wounds)

\section{Inclusion criteria for patients:}

- Adults of both sexes admitted to the surgical unit.

- Patients with open and closed wounds (traumatic and non- traumatic) (e.g., patients with appendisititis, cholesisitites, etc).

- Admitted to emergency operations (traumatic and non-traumatic patients).

\section{Exclusion criteria for patients:}

Patients with burns, and those undergoing orthopedic surgeries 


\section{Tool of data collection:}

Tool I: A structured interview questionnaire:

A structured interview was developed by the researcher to assess the nurses' knowledge about wound care Johnny et al. (2014). It was modified after reviewing the recent relevant literatureandincluded the following parts;

Part 1: Socio-Demographic characteristics of nurses e.g. age, marital status, educational level, years of experience, previous training on wound care.

\section{Part 2: (Wound care knowledge assessment):}

- Knowledge related to wound definition and types (6 MCQ items).

- Knowledge related to wound care (3 MCQ items).

- Knowledge about wound healing (6 MCQ items).

- Knowledge about complications of wound healing (2 MCQ questions and 2 fills in questions).

- The role of nurses regarding standard precautions (16 questions):

- Nurses' knowledge regarding universal precautions (11 true or false questions).

Nurses' role regarding how to prevent transmission of infection (5 true or false questions

\section{TOOL II: Wound healing assessment:}

This tool was used to assess the healing of different types of wounds. This tool was in English language and was translated to Arabic by the researcher and retranslated from English to Arabic to ensure clarity and accuracy. It included two parts:

Open-wound healing assessment tool was adopted fromBates-Jensen scale, (2011). This tool included items used to assess wound healing and how to assess the wound according to its depth, length, size, edge and necrotic tissue.

\section{TOOL III: Protocol for wound care. Its development included the following phases:}

Phase 1: Developing nursing protocol regarding wound care after reviewing relevant literature: (Chou and Conifer, 2012; Canadian Association of Wound Care, 2014; Australian Medicines Handbook, 2015, Taylor, et al., 2017;Lippincott. 2015). This tool contained the following steps; how to assess the wound, how to perform a physical examination for the patient, performing wound care, and open wound dressing. 
Phase 2: Providing an opinionnaire of expertise (for nurses and physicians) regarding the developed protocol of open wound care.

Phase 3: Constructing the final form of the developed wound care protocol based on the results of the opinionnaire of expertise and the relevant literature.

\section{Methods of data collection:}

This study was covered in four phases: -

1-validity of the tool: -. 9 experts were reviewing the content validity of the tool from surgical doctors and medical surgical nursing professor in the field after translation of the tool from English to Arabic language.

\section{2- Reliabilityof the tool:}

Structured interview regarding nurses' knowledge (Cronbach's Alpha $=0.788$ ).

Bates-Jensen scale (Cronbach's Alpha $=0.789)$.

\section{3- Ethical considerations:}

- An informed consent was obtained from the patients and nurses to participate in the study after explaining its aim.

- The researcher assured the study sample of maintaining the anonymity and confidentiality of their data.

- Patients and nurse were informed that they could withdraw from the study at any time.

4- Pilot study: - Pilot study was carried out after the development of the tools on $10 \%$ of the nurses to test applicability of the tools then necessary modification were done according to the results of pilot study and expertise opinions. The purpose of pilot study was:

To test the applicability and feasibility of the study tools. And to estimate any need for addition or omission in the tool, and time needed to fill in the tool.

Otherwise, these nurses were then excluded from the sample of research work to assure the stability of answers

5- Field work: data were collected from two hospitalsat Elmansoura university hospitaland Emergency hospital inElmansoura City at four months from September 2015 
until March2016 for three days weekly mainly Saturday, Sunday and Thursday in the morning shift, each week according to time available to nurses. Each nurse takes time approximately between $30-45$ minutes to fill a questionnaire.

\section{Statistical analysis:}

- The collected data were coded and analysed using the Statistical Package for Social Sciences (SPSS version 20).

- Tabulated frequencies and percentages were calculated.

- The level of significance selected for this study was P-value $\leq 0.05$.

\section{RESULTS:}

Table (1): shows that $95.8 \%$ and $90.3 \%$ of the studied nurses at Mansoura university and emergency hospitals were females.Moreover,the ages of $29.2 \%$ of the nurses at Mansoura hospital ranged from 20 to less than 30 and 30 to less than35years, while at Mansoura emergency hospital, the ages of $25.8 \%$ of the nurses were from 35 to 40 years.Regarding the years of experience, it was found that $58.3 \%$ of the nurses at Mansoura university hospital and $61.3 \%$ of those at Mansoura emergency hospital had an experience of 10 years or more. Moreover, with respect to the years of experience in surgical units, $29.2 \%$ of the nurses at El-Mansoura university hospital, and 38.7\% of the nurses at Mansoura emergency hospital, had 5 to less than 10 years of experience. Concerning the nurses' educational level,77.4\%at Mansoura emergency hospital and 75\% at Mansoura university hospital, had secondary education. Regarding the marital status of the nurses, $100 \%$ of those in Mansoura university hospital were married, compared to87.1\% in Mansoura emergency hospital.

Table (2): shows that pre-protocol., $56.4 \%$ of the studied nurses had unsatisfactory knowledge regarding wound care, while immediately post-protocol., $70.9 \%$ had satisfactory knowledge, and after 12 weeks, $67.3 \%$ had satisfactory knowledge.

Table (3): shows that regarding nurses' knowledge about wound care, $63.4 \%$ of the studied nurses reported correct answers pre-protocol., compared to $96.4 \%$ and $94.6 \%$ of them immediately post-protocol., and 12weeks post-protocol., respectively. Also, regarding nurses' knowledge about wound care, more than half $(61.8 \%)$ of them provided correct answers, while immediately post-protocol., and 12-weeks post protocol., 91.5\% reported 
correct answers. Moreover, regarding nurses' knowledge about wound healing, 51.2\% of them provided correct answers pre-protocol., while immediately post-protocol, this percentage increased to $89.4 \%$. Also, regarding nurses' knowledge about wound complication, less than half of the studied nurses (47.6\%) reported correct answers preprotocol., while immediately post-protocol., and 12 weeks post-protocol., the percentage increased to $90.2 \%$ and $89.1 \%$, respectively.

Table (4): shows that $62.3 \%$ of the studied open-wound patients were less than 50 years old. Regarding gender, most of the studied open-wound (79.2\%) were males, and slightly less than half the studied open were married (47.2\% and $47.3 \%$, respectively). Moreover, concerning the level of education, less than half the open -wound patients were illiterate ( $41.5 \%$ and $42.5 \%$, respectively). Furthermore, $64.2 \%$ and $65.7 \%$ of the studied openwound -wound patients, respectively, were working, and lived in rural residences.

Table (5): shows that $75.5 \%$ of the studied patients had wound degeneration preprotocol., but $83 \%$ immediately post-protocol., and $88.7 \%$ at 12 weeks post-protocol., reported wound regeneration.

Table (6): shows that $62.3 \%$ of the studied patients were less than 50 years old, preprotocol., and whilepost-protocol.Phases, $67.9 \%$ of the patients were less than 50 years old. Regarding patients' genders, 79.2\% pre-protocol.And immediately post-protocol., and $77.4 \%$ after 12 weeks post-protocol., wasmales. Regarding the patients' educational level, $41.5 \%$ of the studied patient's pre-protocol.Were illiterate, while immediately post-protocol., $41.5 \%$ of them were able to read and write. Furthermore, concerning the occupation of the studied patients, $64.2 \%$ pre-protocol., and $73.6 \%$ immediatelypostprotocol.And $67.9 \% 12$ weeks post-protocol.Wasworking. Also, from the studied patients, $64.2 \%$ pre-protocol., and $58.5 \%$ immediately post-protocol?And $52.8 \%$ lived in rural areas. 
Table (1): Distribution of the bio-demographic characteristics of the studied nurses $(\mathrm{N}=55)$.

\begin{tabular}{|c|c|c|c|c|c|c|}
\hline \multirow{3}{*}{ Bio-demographic characteristics } & \multicolumn{4}{|c|}{ Hospital's name } & \multirow{2}{*}{\multicolumn{2}{|c|}{$\begin{array}{c}\text { Total } \\
(\mathrm{N}=\mathbf{5 5})\end{array}$}} \\
\hline & \multicolumn{2}{|c|}{$\begin{array}{c}\text { Mansoura } \\
\text { university } \\
\text { hospital } \\
\quad(n=24)\end{array}$} & \multicolumn{2}{|c|}{$\begin{array}{c}\text { Mansoura } \\
\text { emergency } \\
\text { hospital } \\
\quad(n=31)\end{array}$} & & \\
\hline & No. & $\%$ & No. & $\%$ & No. & $\%$ \\
\hline \multicolumn{7}{|l|}{ 1- Gender: } \\
\hline Male. & 1 & 4.2 & 3 & 9.7 & 4 & 7.3 \\
\hline Female. & 23 & 95.8 & 28 & 90.3 & 51 & 92.7 \\
\hline \multicolumn{7}{|l|}{ 2- Age (years): } \\
\hline $20<25$ & 7 & 29.2 & 6 & 19.4 & 13 & 23.6 \\
\hline $25<30$ & 5 & 20.8 & 5 & 16.1 & 10 & 18.2 \\
\hline $30<35$ & 7 & 29.2 & 8 & 25.8 & 15 & 27.3 \\
\hline $35<40$ & 1 & 4.2 & 9 & 29 & 10 & 18.2 \\
\hline 40 and more & 4 & 16.7 & 3 & 9.7 & 7 & 12.7 \\
\hline Mean \pm SD & \multicolumn{6}{|c|}{$30.69 \pm 7.2$} \\
\hline \multicolumn{7}{|l|}{ 3- Years of experience: } \\
\hline Less than 5 years. & 5 & 20.8 & 9 & 29 & 14 & 25.5 \\
\hline 5 to less than 10. & 5 & 20.8 & 3 & 9.7 & 8 & 14.5 \\
\hline 10 years and more. & 14 & 58.3 & 19 & 61.3 & 33 & 60 \\
\hline Mean \pm SD & \multicolumn{6}{|c|}{$12.2 \pm 7.534$} \\
\hline \multicolumn{7}{|l|}{ 4- Years of experience at surgery unit: } \\
\hline $1<5$ & 10 & 41.7 & 10 & 32.3 & 20 & 36.4 \\
\hline $5<10$ & 7 & 29.2 & 12 & 38.7 & 19 & 34.5 \\
\hline $10+$ & 7 & 29.2 & 9 & 29 & 16 & 29.1 \\
\hline Mean \pm SD & \multicolumn{6}{|c|}{$8.25 \pm 5.552$} \\
\hline \multicolumn{7}{|l|}{ 5- Educational level: } \\
\hline Secondary nursing education. & 18 & 75 & 24 & 77.4 & 42 & 76.4 \\
\hline Technical nursing institution. & 6 & 25 & 7 & 22.6 & 13 & 23.6 \\
\hline \multicolumn{7}{|l|}{ 6- Marital status: } \\
\hline Married. & 24 & 100 & 27 & 87.1 & 51 & 92.7 \\
\hline Widowed. & 0 & 0 & 1 & 3.2 & 1 & 1.8 \\
\hline Divorced. & 0 & 0 & 3 & 9.7 & 3 & 5.5 \\
\hline
\end{tabular}


Table (2): Distribution of the studied nurses regarding their knowledge about wound care $(\mathrm{N}=55)$.

\begin{tabular}{|c|c|c|c|c|c|c|c|}
\hline \multirow{3}{*}{$\begin{array}{l}\text { Total wound care } \\
\text { knowledge }\end{array}$} & \multirow{2}{*}{\multicolumn{2}{|c|}{$\begin{array}{c}\text { Pre- } \\
\text { protocol. }\end{array}$}} & \multicolumn{4}{|c|}{ Post-protocol. } & \multirow{3}{*}{$\begin{array}{l}\text { Freidman test } \\
\text { P-value }\end{array}$} \\
\hline & & & \multicolumn{2}{|c|}{ Immediate } & \multicolumn{2}{|c|}{$\begin{array}{c}\text { After } 12 \\
\text { weeks }\end{array}$} & \\
\hline & No. & $\%$ & No. & $\%$ & No. & $\%$ & \\
\hline Satisfactory & 24 & 43.6 & 39 & 70.9 & 37 & 67.3 & \\
\hline Unsatisfactory & 31 & 56.4 & 16 & 29.1 & 18 & 32.7 & $\begin{array}{l}\text { Freidman (5.682) } \\
\quad \text { P }(0.014) *\end{array}$ \\
\hline
\end{tabular}

* Sig. the p-value for Freidman test $\leq 0.05$

Table (3): Nurses' knowledge pre- and post-implementing the wound care protocol $(\mathrm{N}=55)$.

\begin{tabular}{|c|c|c|c|c|c|c|c|c|c|c|c|c|}
\hline \multirow{3}{*}{$\begin{array}{l}\text { Nurse's wound care } \\
\text { knowledge }\end{array}$} & \multicolumn{4}{|c|}{ Pre-protocol. } & \multicolumn{4}{|c|}{$\begin{array}{l}\text { Immediate post- } \\
\text { protocol. }\end{array}$} & \multicolumn{4}{|c|}{12 weeks post-protocol. } \\
\hline & \multicolumn{2}{|c|}{$\begin{array}{l}\text { Correct } \\
\text { answer }\end{array}$} & \multicolumn{2}{|c|}{$\begin{array}{l}\text { Incorrect } \\
\text { answer }\end{array}$} & \multicolumn{2}{|c|}{$\begin{array}{l}\text { Correct } \\
\text { answer }\end{array}$} & \multicolumn{2}{|c|}{$\begin{array}{l}\text { Incorrect } \\
\text { answer }\end{array}$} & \multicolumn{2}{|c|}{$\begin{array}{l}\text { Correct } \\
\text { answer }\end{array}$} & \multicolumn{2}{|c|}{$\begin{array}{l}\text { Incorrect } \\
\text { answer }\end{array}$} \\
\hline & No. & $\%$ & No. & $\%$ & No. & $\%$ & No. & $\%$ & No. & $\%$ & No. & $\%$ \\
\hline $\begin{array}{l}\text { Nurse's knowledge } \\
\text { about wounds. }\end{array}$ & 35 & 63.4 & 20 & 36.7 & 53 & 96.4 & 2 & 3.6 & 52 & 94.6 & 3 & 5.4 \\
\hline Mean \pm SD & \multicolumn{4}{|c|}{$3.8 \pm 1.4$} & \multicolumn{4}{|c|}{$3.5 \pm 1.2$} & \multicolumn{4}{|c|}{$3.4 \pm 1.1$} \\
\hline $\begin{array}{l}\text { Nurse's knowledge } \\
\text { about wound care. }\end{array}$ & 34 & 61.8 & 21 & 38.2 & 50 & 91.5 & 5 & 8.5 & 50 & 91.5 & 5 & 8.5 \\
\hline Mean \pm SD & \multicolumn{4}{|c|}{$1.8 \pm 0.8$} & \multicolumn{4}{|c|}{$1.6 \pm 0.7$} & \multicolumn{4}{|c|}{$1.7 \pm 0.4$} \\
\hline $\begin{array}{l}\text { Nurse's knowledge } \\
\text { about wound healing. }\end{array}$ & 28 & 51.2 & 27 & 48.8 & 49 & 89.4 & 6 & 10.6 & 49 & 75.4 & 6 & 11.2 \\
\hline Mean $\pm \mathrm{SD}$ & \multicolumn{4}{|c|}{$3.07 \pm 1.2$} & \multicolumn{4}{|c|}{$3.06 \pm 1.1$} & \multicolumn{4}{|c|}{$3 \pm 1.1$} \\
\hline $\begin{array}{l}\text { Nurse's knowledge } \\
\text { about complications of } \\
\text { wounds. }\end{array}$ & 26 & 47.6 & 29 & 52.4 & 50 & 90.2 & 5 & 9.8 & 49 & 89.1 & 6 & 10.9 \\
\hline Mean $\pm \mathrm{SD}$ & \multicolumn{4}{|c|}{$2.3 \pm 0.9$} & \multicolumn{4}{|c|}{$2.1 \pm 0.8$} & \multicolumn{4}{|c|}{$2.3 \pm 0.9$} \\
\hline $\begin{array}{l}\text { Nurse's knowledge } \\
\text { about infection control } \\
\text { measures/ universal } \\
\text { precaution during } \\
\text { wound care. }\end{array}$ & 31 & 55.9 & 24 & 44.1 & 49.8 & 90.6 & 5 & 9.4 & 47 & 85.9 & 8 & 14.1 \\
\hline Mean \pm SD & \multicolumn{4}{|c|}{$5.3 \pm 1.9$} & \multicolumn{4}{|c|}{$5.1 \pm 1.7$} & \multicolumn{4}{|c|}{$4.8 \pm 1.2$} \\
\hline $\begin{array}{l}\text { Nurse's knowledge } \\
\text { about nurses' role to } \\
\text { control wound } \\
\text { infection. }\end{array}$ & 28 & 50.1 & 27 & 49.9 & 51 & 93.4 & 4 & 6.6 & 51 & 93.1 & 4 & 6.9 \\
\hline Mean \pm SD & \multicolumn{4}{|c|}{$3.3 \pm 1.1$} & \multicolumn{4}{|c|}{$2.7 \pm 0.9$} & \multicolumn{4}{|c|}{$2.3 \pm 0.93$} \\
\hline
\end{tabular}


Table (4) Socio-demographic characteristics of the patients with open wound

\begin{tabular}{|c|c|c|}
\hline \multirow{2}{*}{$\begin{array}{c}\text { Socio-demographic } \\
\text { characteristics }\end{array}$} & \multicolumn{2}{|c|}{ "Open-wound patients $(\mathrm{N}=53)$} \\
\hline & No. & $\%$ \\
\hline \multicolumn{3}{|l|}{ Age (Years) } \\
\hline $20<25$ & 10 & 18.8 \\
\hline $25<30$ & 9 & 16.9 \\
\hline $30<35$ & 15 & 28.3 \\
\hline $35<40$ & 4 & 7.5 \\
\hline 40 and 50 & 5 & 9.4 \\
\hline More than 50 & 10 & 18.8 \\
\hline Mean \pm SD & \multicolumn{2}{|c|}{$39.28 \pm 19.38$} \\
\hline \multicolumn{3}{|l|}{ Sex } \\
\hline Male & 42 & 79.2 \\
\hline Female & 11 & 20.8 \\
\hline \multicolumn{3}{|l|}{ Marital status } \\
\hline Single & 17 & 32.1 \\
\hline Married & 25 & 47.2 \\
\hline Widowed & 7 & 13.2 \\
\hline Divorced & 4 & 7.5 \\
\hline \multicolumn{3}{|l|}{ Level of education } \\
\hline Illiterate & 22 & 41.5 \\
\hline Primary & 19 & 35.8 \\
\hline Preparatory & 7 & 13.2 \\
\hline Secondary & 4 & 7.5 \\
\hline University & 1 & 1.9 \\
\hline \multicolumn{3}{|l|}{ Occupation } \\
\hline Working & 34 & 64.2 \\
\hline Non-working & 19 & 35.8 \\
\hline \multicolumn{3}{|l|}{ Place of residence } \\
\hline Rural & 34 & 64.2 \\
\hline Urban & 19 & 35.8 \\
\hline
\end{tabular}

Table (5): Wound healing based on Bates-Jensen wound continuum among studied open-wound patients $(\mathrm{N}=53)$.

\begin{tabular}{|c|c|c|c|c|c|c|c|}
\hline \multirow{3}{*}{$\begin{array}{c}\text { Bates-Jensen } \\
\text { wound condition }\end{array}$} & \multirow{2}{*}{\multicolumn{2}{|c|}{$\begin{array}{c}\text { Pre- } \\
\text { program } \\
(\mathrm{N}=53)\end{array}$}} & \multicolumn{4}{|c|}{ Post-protocol. } & \multirow{3}{*}{$\begin{array}{c}\text { Freidman test } \\
\text { P-value }\end{array}$} \\
\hline & & & \multicolumn{2}{|c|}{$\begin{array}{c}\text { Immediate } \\
(\mathbf{N}=53)\end{array}$} & \multicolumn{2}{|c|}{$\begin{array}{c}\text { After } 12 \\
\text { weeks } \\
(\mathrm{N}=53)\end{array}$} & \\
\hline & No. & $\%$ & No. & $\%$ & No. & $\%$ & \\
\hline Wound degeneration & 40 & 75.5 & 9 & 16.9 & 6 & 11.3 & $\begin{array}{c}\text { Freidman test } \\
(10.055)\end{array}$ \\
\hline Wound regeneration & 13 & 24.5 & 44 & 83 & 47 & 88.7 & $\mathrm{P}^{*} 0.000$ \\
\hline
\end{tabular}

* Sig: P-value $\leq 0.05$ 
Table (6): Distribution of the open-wound patients at El-Mansoura university and emergency hospitals according to their Bates-Jensen wound condition (pre- and postprogram) and their socio-demographic characteristics $(\mathrm{N}=53)$

\begin{tabular}{|c|c|c|c|c|c|c|c|c|c|c|c|c|c|c|c|c|c|c|c|c|c|}
\hline \multirow{5}{*}{$\begin{array}{c}\text { Socio- } \\
\text { demographic } \\
\text { characteristic }\end{array}$} & \multirow{2}{*}{\multicolumn{7}{|c|}{ Preprotocol. }} & \multicolumn{14}{|c|}{ Post-protocol. } \\
\hline & & & & & & & & \multicolumn{7}{|c|}{ Inimediate } & \multicolumn{7}{|c|}{ After 12 weels } \\
\hline & \multicolumn{21}{|c|}{ Bates Jensen Wound Continumam } \\
\hline & \multicolumn{2}{|c|}{$\begin{array}{c}\text { Wound } \\
\text { rtgantion } \\
(\mathrm{N}=13)\end{array}$} & \multicolumn{2}{|c|}{ 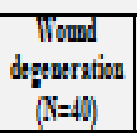 } & \multicolumn{2}{|c|}{$\begin{array}{c}\text { Total } \\
(\mathrm{N}=53)\end{array}$} & \multirow{2}{*}{$\begin{array}{c}X^{2} \\
\text { P- } \\
\text { ralue }\end{array}$} & \multicolumn{2}{|c|}{ 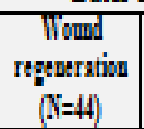 } & \multicolumn{2}{|c|}{$\begin{array}{c}\text { Wowd } \\
\text { degernaion } \\
(\mathrm{A}=y)\end{array}$} & \multicolumn{2}{|c|}{$\begin{array}{c}\text { Total } \\
(\mathrm{N}=\mathbf{5})\end{array}$} & \multirow{2}{*}{$\begin{array}{c}X^{2} \\
\text { P-ralue }\end{array}$} & \multicolumn{2}{|c|}{$\begin{array}{c}\text { Womed } \\
\text { Ingurnation } \\
(\mathrm{N}=\mathrm{A})\end{array}$} & \multicolumn{2}{|c|}{$\begin{array}{c}\text { Wound } \\
\text { degaunation } \\
(\mathrm{N}=6)\end{array}$} & \multicolumn{2}{|c|}{$\begin{array}{c}\text { Total } \\
(\mathrm{N}=\$ 3)\end{array}$} & \multirow{2}{*}{$\begin{array}{c}X^{2} \\
\text { P-ralue }\end{array}$} \\
\hline & Mo. & 9 & Mo. & 9 & $\mathrm{~N}_{0}$ & 96 & & $\mathrm{~N}_{0}$ & 9 & $\mathrm{~N}_{0}$ & 40 & No. & 96 & & Mo. & 96 & Mo. & 96 & Mo. & 96 & \\
\hline \multicolumn{22}{|l|}{ Age(Years) } \\
\hline Les than 30 & 9 & 62 & 24 & 60 & 3 & 63 & \multirow{2}{*}{$\begin{array}{c}x^{6}(239) \\
P 04\end{array}$} & 9 & 699 & 7 & 778 & 3 & 69 & \multirow{2}{*}{$\begin{array}{c}x^{2}(33) \\
p 039\end{array}$} & \$I & 66 & 5 & B! & 36 & 59 & \multirow{2}{*}{$\begin{array}{l}x^{6}(42) \\
2036 \\
\end{array}$} \\
\hline Nore than 50 & 4 & 30 & 16 & 40 & 2 & $379 ?$ & & 15 & 34.1 & 2 & $m$ & 17 & 31 & & 16 & 34 & 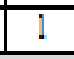 & 167 & 17 & 321 & \\
\hline \multicolumn{22}{|l|}{ Serr } \\
\hline Mala & 12 & $M 1$ & $\mathbb{0}$ & $\pi$ & 42 & 72 & \multirow{2}{*}{$\begin{array}{l}f^{2}(2.12) \\
\text { po.17 }\end{array}$} & 3 & $\eta$ & 9 & $1 \mathrm{M}$ & 42 & 72 & \multirow{2}{*}{$\begin{array}{c}x^{2}(3.15) \\
p 010\end{array}$} & 36 & 76 & 5 & B! & $4 !$ & 77.4 & \multirow{2}{*}{$\begin{array}{c}x^{6}(996) \\
P 08 \\
\end{array}$} \\
\hline Fenale & 1 & 71 & 10 & 3 & 11 & Ms & & II & 3 & 0 & 0 & II & $M S$ & & II & 34 & 1 & 16 & 11 & $\mathrm{Mb}$ & \\
\hline \multicolumn{22}{|l|}{ Iducation } \\
\hline Illiterate & 5 & 31 & 17 & 42 & $\bar{M}$ & 415 & & 15 & 34.1 & 2 & 21 & 17 & 31 & & 4 & $B$ & 0 & 0 & 4 & 73 & \\
\hline Read and wits & 4 & 38 & 15 & 315 & 19 & 35 & & 17 & 316 & 5 & 38.6 & $n$ & 41.5 & & 15 & 319 & 1 & 167 & 15 & 30 & \\
\hline Minary & 2 & 11.4 & 5 & 12 & 7 & 132 & $p 0$ & $?$ & 139 & 2 & $\mathrm{~m}$ & 9 & 17 & 879 & 9 & 191 & $!$ & 167 & 10 & 189 & $(43)$ \\
\hline Prepratory & 2 & 11.4 & 2 & 5 & 4 & 75 & & 4 & 9.1 & 0 & 0 & 4 & 79 & & 18 & 33 & 4 & 66 & $n$ & 41.5 & \\
\hline Averas & 0 & 0 & 1 & 25 & 1 & 19 & & 1 & 13 & 0 & 0 & 1 & 19 & & 1 & 21 & 0 & 0 & ! & 19 & \\
\hline Occupatiou & & & & & & & & & & & & & & & & & & & & & \\
\hline Towking & 7 & 59 & $\bar{B}$ & $\pi$ & 40 & 737 & 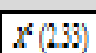 & 30 & 61. & 9 & 100 & 9 & 736 & $x^{6}(211)$ & II & 6 & 5 & 83 & 36 & 67 & $x^{(433)}$ \\
\hline Non-woiking & 6 & $46 ! 1$ & 12 & 8 & 13 & 2432 & P0.46 & 14 & 318 & 0 & 0 & 14 & 34 & P40. & 16 & 34 & 1 & 167 & 17 & 321 & $8036^{\prime}$ \\
\hline Thace of ruideace & & & & & & & & & & & & & & & & & & & & & \\
\hline Rural & 9 & 61 & S & 61 & 34 & 642 & \begin{tabular}{|l}
$I^{6}(3.18)$ \\
\end{tabular} & $\bar{M}$ & 30 & 9 & $\overline{100}$ & 31 & 55 & $x^{6}(66)$ & M & 46 & 6 & IM & $\pi$ & 52 & $R^{\prime}(3)$ \\
\hline Diban & 4 & $M$ & 15 & 315 & 19 & 38 & $20.46^{\circ}$ & $n$ & 0 & 0 & 0 & $n$ & 41.5 & $700^{\circ}$ & 3 & 32 & 0 & 0 & 3 & 472 & P401 \\
\hline
\end{tabular}

* Significant at P-value $\leq 0.05$

\section{DISCUSSION:}

Nurses are considered the "heart and soul" of every hospital. Nurses' knowledge plays a significant role to controlwound infections, which ultimately enhances the quality of patients' care (Paudyal et al., 2015).

The current study was conducted with the aim of evaluating the effect of a wound care protocol on nurses' knowledge, practice and patients' wound healing. We showed the effectiveness of wound care protocol in wound healing of post-surgical operations in patients who were admitted in two hospitals, Mansoura University and emergency hospitals. All aspects of skin and soft tissue wounds, including acute surgical wounds, pressure ulcers and all forms of wounds, were encompassed in the specialty of tissue viability. 
The present study indicates that the females nurses were more prevalent than male, concerning to their age, less than half of them their age ranged from 20 to 25 and from 30 to 35 years old in Mansoura university hospital but in the emergency hospital, the nurse's age ranged from 30 to 40 years old. Concerning years of experience, more than half of studied nurses have 10 years and more in both hospitals. however, years of experience at surgery unit, less than half of them were more than five years in Mansoura university hospital and inEmergency hospital less than half of studied nurses have 5 to less than 10 years' experience. Additionally, more than half of nurses included in the present study have a diploma in nursing, except some of the nurses have a technical nursing institution. Otherwise, all nurses in the present study were married The present study revealed that more than half of the studied nurses before the protocol had unsatisfactory knowledge regarding wound care; this might have been related to the nurses' lack of training, However, nurses' knowledge became satisfactory post the protocol regarding wound care implementation, and during follow-up.

These results go in the same line with those of Basra et al. (2014); Williams and Buckless, (2014) who reported that nurses' knowledge scores regarding wound care were unsatisfactory. On the other hand, the studied nurses' knowledge increased significantly immediately after implementing the protocol regarding wound care.The deficient knowledge among the study sample in the two hospitals may have beendue to the absence of staff developmental activities such as attending lectures and/or conferences to refresh knowledge regarding wound care. Also, it could have been due to the lack of appropriate studied courses.

Moreover, regarding the nurses' knowledge about the wounds in the present study, more than half of them had unsatisfactory knowledge about wounds before the implementation of the protocol, however, this percentage increased immediately after the protocol implementation and during the follow-up after three months.

Regarding the nursing knowledge on the technique of wound care, the present study showed that more than half of the studied nurses had unsatisfactory knowledge before the implementation of the protocol, but this percentage increased after the implementation of the protocol of wound care, and also continued during the follow-up after three months of the protocol implementation. Moreover, less than half of the nurses had satisfactory knowledge regarding wound healing before the implementation of the wound care protocol, however, this improved significantly post-program implementation and during follow-up. 
Furthermore, less than half of the nurses had unsatisfactory knowledge regarding the complications of wounds before the implementation of the protocol. This changed to satisfactory knowledge after the protocol implementation directly and during the followup after three months. The World Health Organization, WHO (2015), has set a number of recommendations towards prevention of surgical site infections, these include avoidance of pre-operative hair removal, advice for pre-operative showering, hand hygiene, appropriately and timely administration of antibiotics, pre- and post-operative glycemic control, wound management, nutritional assessment and surgical site preparation, etc. (Hollander et al., 2015). In order to apply such recommendations, the nurses must be knowledgeable to provide a qualified wound care.

The current study highlighted that the knowledge of more than half the study sample regarding infection control measures and comprehensive precautions during wound care, before the implementation of the protocol, was unsatisfactory. However, this percentage increased after the immediate protocol implementation and during follow-up after three months. Also, the nurses 'knowledge regarding controlling the wound infection was unsatisfactory before the application of the protocol, but increased immediately after the protocol implementation and during the follow-up after three months.

\section{CONCLUSION:}

Based on the results of the current study, it can be concluded that; nurses attending the designed educational protocol. regarding wound care showed improved levels of knowledge. This was manifested by improvement in patients' wound healing. Therefore, the implementations of an educational protocol.for nurses about wound care has positive effects on wound regeneration.

\section{RECOMMENDATIONS:}

Given the most important study findings, the following recommendations are suggested.

\section{For nurses}

Nurses' knowledge about surgical wound care, and infection control in general, needs to be updated through in-service training protocol.

Several educational components should be combined into concise, efficient, and effective recommendations that could be easily understood and remembered. 
The wound care nurse service is incorporated as a new level of health care to improve outcomes and quality of life for patients with wounds.

\section{REFERENCES:}

Allen D.B., Maguire J.J., Mahdavian M., Wicke C., Marcocci L., and Scheuenstuhl H. (2013). Wound Hypoxia and Acidosis Limit Neutrophil Bacterial Killing Mechanisms. Arch Surg; 132: 991-996

Australian Medicines Handbook (Internet) (2015). Monitoring pressure ulcer healing in persons with disabilities. RehabilNurs; 30(3):92-9.

Bates-Jensen BM. (2011). The pressure sore status tool: a few thousand assessments later. Adv Wound Care.73-10:65

Bonham M.A. (2014).Report of the task force on the implications for darkly pigmented intact skin in the prevention of pressure ulcers. Adv Wound Care; 8:34-35

Canadian Association of Wound Care (2014): Evaluation of Blunt Suture Needles in Preventing Percutaneous Injuries Among Health-Care Workers during Gynecologic Surgical Procedures, New York City, March 2014-June 2013. MMWR Morb Mortal Wkly Rep; 46(2): 25-9.

Centres for Disease Control and Prevention, CDC (2010). National Nosocomial Infections Surveillance (NNIS) report, data summary from October 2000-April 2001, issued May 2001. Am J Infect Control; 25: 477-487

Chicano S.G., Drolshagen C. (2015). Reducing hospital-acquired pressure ulcers. J Wound Ostomy Continence Nurs 2015; 36:45-50.

Chou \& Conifer (2012).Post surgical Infections Associated with Nonsterile Implantable Devices. MMWR Morb Mortal Wkly Rep; 41(15): 263.

Falanga M.S. (2015): Is Eliminating Flash Sterilization Practical? Infect Control Hosp Epidemiol; 14(8): 479-80.

Johnny et al. (2014). A prospective evaluation of emergency department bedside ultrasonography for the detectionof acute cholecystitis. Ann Emerg Med. 2010;pp 115-121. 
Lazarus W.T., Talbot T.L., Norton J.A. (2016). Preoperative or postoperative doxorubicin hydrochloride (Adriamycin): which is better for wound healing? Surgery 100:9-13 [Pub Med],

McDermott-Scales et al. 2014).Acute calculous cholecystitis. NEngl JMed.;358:2804-2811.

Nichols R.L. (2014). The Operating Room. In: Bennett J.V., and Brachman P.S. (Eds.): Hospital Infections. $3^{\text {rd }}$ ed., Boston: Little, Brown and Co. pp. 461-73.

O'Brien et al. (2016).diagnosis of bile duct calculi. Results of a prospective study of 222 cases of choledocholithiasis. Ultrachall Med;8: pp 116.243

Schultz et al. (2013). Patient safety and quality: An evidence-based handbook fornurses. Rockville, MD: Agency for Healthcare Research and Quality, US. pp 121-130

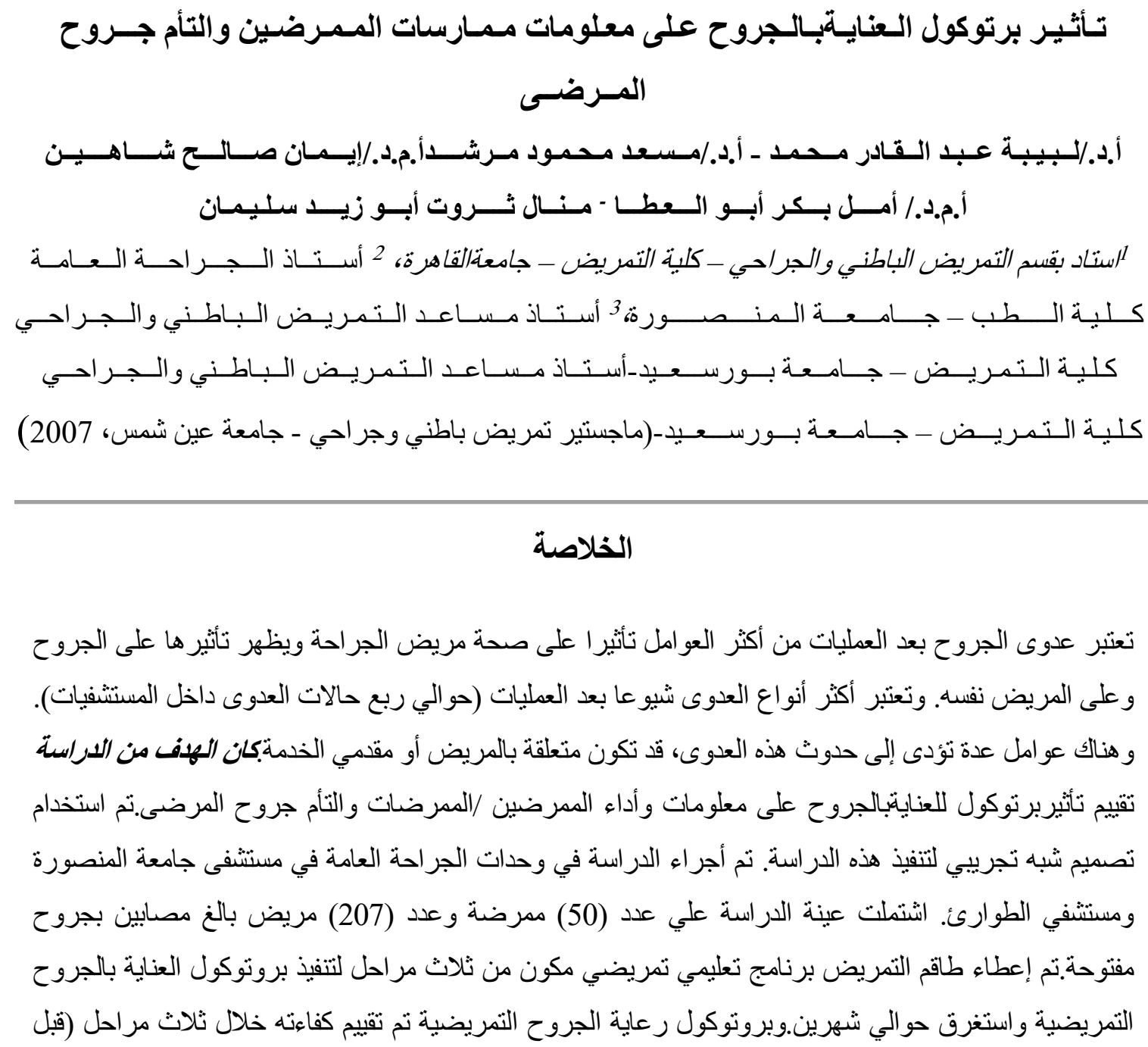


البرنامج، بعده، ومتابعة بعد 12 أسبوع).أظهرت نتائج الدر اسة تحسنا معنويا بين أفراد الدر اسة في حالة التنئام الجروح

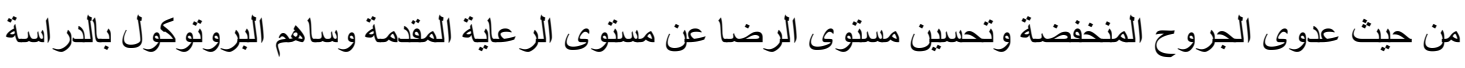

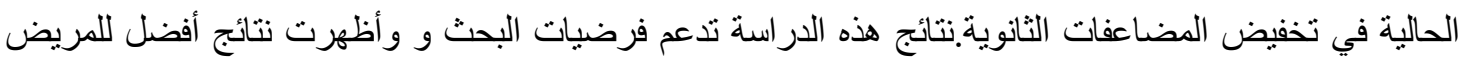
أثناء البرنامج و عند المتابعة بالمقارنة مع حاله المرضى قبل البرنامج. 